\title{
Comparison of Two Approaches for Generation of Daily Rainfall Data
}

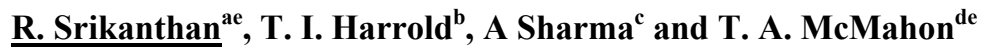 \\ ${ }^{a}$ Hydrology Unit, Bureau of Meteorology, Melbourne, Australia. Email: r.Srikanthan@bom.gov.au \\ ${ }^{b}$ Research Institute for Humanity and Nature, 335 Takashima-cho, Kamigyo-ku, Kyoto 602-0878, Japan, \\ ${ }^{c}$ Department of Civil Engineering, University of New South Wales, Sydney, Australia, \\ ${ }^{\mathrm{d}}$ Department of Civil and Environmental Engineering, University of Melbourne, Melbourne, Australia, \\ ${ }^{\mathrm{e}}$ Cooperative Research Centre for Catchment Hydrology, Monash University, Clayton, Australia.
}

\begin{abstract}
Models for generating daily rainfall are in great demand for various needs and have seen much development. Srikanthan and McMahon (1985) showed that the transition probability matrix (TPM) model performed better than alternative models available then. However a noted shortcoming is the underestimation of the variances of the simulated monthly and annual rainfall. Boughton (1999) proposed an empirical adjustment to match the observed annual standard deviation, which although improves the variability in the annual rainfall, still underestimates the variability in the annual number of wet days. Recently, Harrold et al. (2002) proposed nonparametric models for the generation of daily rainfall occurrences and rainfall amounts on wet days. The rainfall occurrence model was conditioned on a combination of daily, seasonal, annual, and multi-year predictors. By conditioning on short, medium and long-term characteristics, this model was able to preserve the variability in the annual number of wet days. The model to generate the rainfall depth also used a combination of short and long term predictors which consisted of the rainfall depth on the previous day and an indicator of the annual rainfall total. This model also differed from the TPM model in the representation of seasonality in the rainfall simulations by a seasonal moving window. The above two approaches were compared by generating daily rainfall data for Melbourne and Sydney. Both approaches preserved most of the daily, monthly and annual characteristics but failed to preserve the correlations in monthly and annual rainfall. However, the nonparametric approach was able to preserve the variability and persistence in the annual number of wet days.
\end{abstract}

Keywords: Stochastic generation; Daily rainfall, Transition probability matrix; Nonparametric approach

\section{INTRODUCTION}

Daily rainfall is a major input to the design of water resources and agricultural systems. As historical data provides only one realisation of the underlying climate, stochastically generated data is used to assess the impact of climate variability on water resources and agricultural systems. The transition probability matrix (TPM) model (Srikanthan and McMahon, 1985) is widely used in Australia for stochastic generation of daily rainfall, and it appears to preserve most of the characteristics of daily, monthly and annual rainfall. While it performs better than many alternative models, it consistently underrepresents the variances of the observed monthly and annual rainfall. Boughton (1999) proposed an empirical adjustment to match the observed annual standard deviation. The adjustment factor can be explicitly derived as the ratio of the standard deviations of the generated and observed annual data. This adjustment improves the variability in the annual rainfall by scaling the rainfall amounts on wet days. Recently, an alternative approach involving nonparametric models for the generation of both daily rainfall occurrences and rainfall amounts on wet days was proposed by Harrold et al. (2002). This paper applies both the TPM approach and the approach of Harrold et al. (2002) to stochastically generate daily rainfall data for Melbourne and Sydney, and a number of daily, monthly and annual characteristics are used to compare the results of each approach.

\section{TRANSITION PROBABILITY MATRIX METHOD}

The model used in this study is a variation of the algorithm developed by Srikanthan and McMahon (1985). The rainfall amount of the last state is modelled by a shifted Gamma distribution instead of the Box-Cox transformation used in the original model. An empirical adjustment factor (Boughton, 1999) is incorporated to preserve the standard deviation of the annual rainfall. 
In the Transition Probability Matrix (TPM) model, the seasonality in occurrence and magnitude of daily rainfall are taken into account by considering each month separately. The daily rainfall is divided into a number of states, up to a maximum of seven. State 1 is dry (no rainfall) and the other states are wet. The number of states for each month can be determined from the guidance given in Srikanthan and McMahon (1985).

The shifted Gamma distribution is used to model rainfall amounts for the last state, while a linear distribution is used for the intermediate states. The latter is chosen because daily rainfall usually exhibits a $\mathrm{J}$ shape distribution.

The transition probabilities are estimated from

$$
p_{i j}(k)=\frac{f_{i j}(k)}{\sum_{j=1}^{C} f_{i j}(k)} i, j=1, \ldots, C ; k=1, \ldots, 12
$$

where $f_{i j}(k)=$ historical frequency of transition from state $\mathrm{i}$ to state $\mathrm{j}$ within month $\mathrm{k}$, and

$C=$ the maximum number of states.

The Gamma distribution parameters are obtained by the method of moments.

The model can be improved by adopting an empirical adjustment factor $(F)$ to match the observed standard deviation of the annual rainfall (Boughton, 1999). The generated daily rainfall in each year is multiplied by the following ratio:

$$
\text { Ratio }_{i}=\frac{\left\{M+\left(T_{i}-M\right) F\right\}}{T_{i}}
$$

where $M$ is the generated mean annual rainfall and $T_{i}$ the generated annual rainfall for year $i$.

Since the slope of the frequency curve is proportional to the standard deviation, the adjustment factor can be directly obtained as a ratio of the standard deviation of the generated and observed annual rainfall. Thus:

$$
F=\frac{s t d e v_{g}}{s t d e v_{o}}
$$

The standard deviation of the generated annual rainfall is estimated from a number of replicates and averaged. The ratio of this generated value to the observed value is taken as $F$ for adjusting the daily values. It should be noted that while this adjustment improves the representation of rainfall characteristics at the annual scale, it comes at the cost of inflating the variability at the daily time scale.

\section{NONPARAMETRIC MODEL}

The nonparametric model (Harrold et al. 2002) consists of two parts: a rainfall occurrence model and a rainfall amounts model. The rainfall occurrence model is designed to smoothly reproduce the seasonality of the historical record and to reproduce the observed characteristics of the historical record at several time scales. Seasonality is modelled using the moving window approach (Rajagopalan et al. 1996; Sharma and Lall, 1999). A 15-day moving window is centred at the current calendar day, and all days falling within the moving window form the local subset of data used in the model for the current day. This ensures a smooth transition of generated rainfall characteristics throughout the year. Actual simulation proceeds using nearest-neighbour resampling (Lall et al., 1996; Sharma and Lall, 1999). This is a data resampling strategy that approximates the random mechanism that produced the historical data. In this methodology, a pattern is chosen from the historical sequence that is similar to the current pattern in the generated sequence, and the successor to the chosen pattern is placed into the generated sequence. The patterns that are examined are those that exist in the predictor set used in the model. The predictor set used for Sydney and Melbourne rainfall occurrence is:

1. Rainfall occurrence on the previous day

2. The wetness state (very dry, dry, average, wet or very wet) for the previous 90 days.

3. The wetness state for the previous year leading up to the current day.

4. The wetness state for the previous four or five years leading up to the current day.

These predictors are chosen to represent both short-term and long-term dependence in the simulated rainfall.

The model to generate the rainfall depth also used a short-term and a longer-term predictor. In addition, daily rainfall amounts are separated into four separate classes: class 0 solitary wet days, class 1a days at the start of wet spells, class $1 \mathrm{~b}$ days at the end of wet spells and class 2 intermediate days within wet spells. Another feature of the Harrold et al. (2002) model that differed from the TPM model was the representation of seasonality in the rainfall simulations. A 31-day moving window was used to ensure a smooth transition of generated rainfall characteristics throughout the year, whereas the use of a monthly discretisation in formulating the TPM resulted in an abrupt transition across month boundaries. 
The model for the generation of rainfall amounts has two predictors, namely, the rainfall amount on the previous day and the wetness state for the preceding 365 days (very dry, dry, average, wet or very wet based on the number of wet days). The observations $x_{i}$ are separated into five data sets according to the historical values of the wetness state. The model is implemented using kernel estimation of the probability densities (Sharma et al., 1997; Sharma and O’Neill, 2002). Kernel density estimation methods form a smoothed empirical probability distribution from the historical record and generate values from this distribution. A univariate kernel probability density estimator is written as:

$$
\hat{f}_{X}(x ; h)=\frac{1}{n h} \sum_{i=1}^{n} K\left(\frac{x-x_{i}}{h}\right)
$$

where $x_{i}$ is the $i^{\text {th }}$ data point in a sample of size $n$, $K()$ is a kernel function that must integrate to 1 and $h$ is the bandwidth of the kernel used in estimating the probability density function. A Gaussian kernel is used and a bandwidth selected by the method of Silverman (1986). The bandwidth selected by this method is:

$h=0.3 R n^{-1 / 5}$

where $\mathrm{R}$ is the interquartile range of the data.

Simulation Class 0 and Class 1a amounts $\left(x_{t}\right)$ proceeds as follows:

1. Form a seasonal subsample $(X)$ of $n$ Class 0 (or Class 1a) amounts from the historical record.

2. Pick an $\left(x_{i}\right)$ value with probability $1 / n$.

3. Select $x_{t}$ as a random variate from the kernel centred on $x_{i}$ :

$x_{t}=x_{i}+h W_{i}$

where $W_{i}$ is a random variate from a normal distribution with mean 0 and unit variance.

Equation (6) can generate zero or negative values for the rainfall amounts. To get around this problem, a variable kernel and boundary renormalisation (Sharma and O'Neill, 2002) are used near the threshold value of $0.3 \mathrm{~mm}$. Simulation of Class $1 \mathrm{~b}$ and Class 2 amounts proceeds in a similar way except that the $x_{i}$ values are selected conditionally and the bandwidth $(h)$ is also calculated using conditional values of $R$ and $n$. Further details on this methodology can be found in Harrold (2002).

\section{MODEL EVALUATION}

The model evaluation is carried out at daily, monthly and annual time periods. The parameters used to evaluate at the daily level are:

- number of wet days and maximum daily rainfall

- mean, standard deviation and coefficient of skewness of daily rainfall

- correlation between the rainfall depth $(\mathrm{mm})$ and duration (days), for all wet spells in a month

- mean rainfall on different types of wet days

- mean, standard deviation and coefficient of skewness of dry and wet spell lengths

- maximum dry and wet spell lengths

- correlation between daily rainfall for Class 2 wet days

At the monthly level, mean, standard deviation, coefficient of skewness, serial correlation, maximum and minimum monthly rainfall and number of months of no rainfall are compared. The maximum and minimum are standardised by the non-seasonal monthly mean. At the annual level, the first six of the above statistics, adjusted range and low rainfall sums of 2-, 3-, 5- and 10year durations are compared. In addition, the mean, standard deviation and the lag one autocorrelation coefficient of the annual number of wet days and the standard deviation of 2-, 3-, 5- and 10- year rainfall sums are also compared. The maximum, minimum and the range are standardised by the mean annual rainfall.

\section{DISCUSSION OF RESULTS}

One hundred replicates, each of length 125 years were generated for Melbourne and Sydney. The number of states used in the TPM model for Melbourne and Sydney are 6 and 7 respectively for all the months. The daily, monthly and annual parameters mentioned in Section 4 were estimated from the replicates and averaged. The average values are used to evaluate the models. Due to lack of space, not all the results are presented.

\subsection{Daily Parameters}

Comparison of the historical and daily parameters is given in Tables 1 to 6 . Only the results for one month from each season are presented. Both models preserved the number of wet days, maximum daily rainfall, correlation between rainfall depth and duration (Table 1), moments of daily rainfall (Table 2), mean rainfall on different types of wet days (Table 3), moments of the dry (Table 4) and wet spells (Table 5) and maximum dry and wet spells (Table 6) satisfactorily. It can 
Table 1. Comparison of historical and generated number of wet days, maximum daily rainfall ( $\mathrm{mm})$ and correlation between rainfall depth and duration for all wet spells in a given month.

\begin{tabular}{|c|c|c|c|c|c|c|c|c|c|c|c|c|c|}
\hline & & \multicolumn{4}{|c|}{ Number of wet days } & \multicolumn{4}{|c|}{ Maximum daily rainfall (mm) } & \multicolumn{4}{|c|}{$\begin{array}{c}\text { Correlation between rainfall } \\
\text { depth and duration }\end{array}$} \\
\hline & \multirow[b]{2}{*}{ His } & Jan & Apr & Jul & Oct & Jan & Apr & Jul & Oct & Jan & Apr & Jul & Oct \\
\hline \multirow{3}{*}{ Sydney } & & 12.2 & 13.0 & 11.4 & 11.8 & 191 & 165 & 198 & 162 & 0.68 & 0.65 & 0.72 & 0.67 \\
\hline & TPM & 11.9 & 13.0 & 11.3 & 11.6 & 219 & 182 & 177 & 171 & 0.66 & 0.73 & 0.73 & 0.66 \\
\hline & NP & 11.9 & 13.0 & 11.1 & 11.7 & 204 & 200 & 196 & 166 & 0.65 & 0.67 & 0.71 & 0.65 \\
\hline \multirow{3}{*}{ Melbourne } & His & 8.2 & 12.1 & 16.6 & 14.4 & 108 & 80 & 74 & 61 & 0.65 & 0.64 & 0.62 & 0.67 \\
\hline & TPM & 8.0 & 11.8 & 16.1 & 14.1 & 85 & 77 & 68 & 67 & 0.65 & 0.68 & 0.70 & 0.73 \\
\hline & NP & 8.0 & 11.8 & 15.8 & 14.0 & 93 & 76 & 62 & 62 & 0.63 & 0.66 & 0.68 & 0.70 \\
\hline
\end{tabular}

Table 2. Comparison of historical and generated mean, standard deviation and coefficient of skewness of daily rainfall.

\begin{tabular}{|c|c|c|c|c|c|c|c|c|c|c|c|c|c|}
\hline \multirow[t]{2}{*}{ Site } & & \multicolumn{4}{|c|}{ Mean (mm) } & \multicolumn{4}{|c|}{ Standard deviation (mm) } & \multicolumn{4}{|c|}{ Skewness } \\
\hline & & Jan & Apr & Jul & Oct & Jan & Apr & Jul & Oct & Jan & Apr & Jul & Oct \\
\hline \multirow{3}{*}{ Sydney } & His & 8.5 & 9.3 & 8.6 & 6.7 & 16.4 & 17.0 & 16.1 & 13.2 & 5.24 & 4.00 & 4.26 & 5.27 \\
\hline & TPM & 8.7 & 9.5 & 9.0 & 7.1 & 16.6 & 16.7 & 16.5 & 13.6 & 5.29 & 3.86 & 4.15 & 5.24 \\
\hline & $\mathrm{NP}$ & 8.8 & 9.6 & 8.7 & 6.9 & 17.6 & 17.6 & 15.9 & 13.4 & 5.60 & 4.31 & 4.37 & 5.24 \\
\hline \multirow{3}{*}{ Melbourne } & His & 5.9 & 4.9 & 2.9 & 4.7 & 9.6 & 7.7 & 4.7 & 6.6 & 3.49 & 3.80 & 5.29 & 3.19 \\
\hline & TPM & 6.1 & 5.1 & 3.1 & 5.0 & 9.7 & 7.8 & 4.8 & 6.7 & 3.25 & 3.68 & 5.01 & 3.22 \\
\hline & NP & 6.0 & 5.1 & 3.0 & 4.8 & 9.8 & 7.9 & 4.6 & 6.7 & 3.36 & 3.58 & 4.79 & 3.39 \\
\hline
\end{tabular}

Table 3. Comparison of historical and generated mean rainfall $(\mathrm{mm})$ on different types of wet days.

\begin{tabular}{|c|c|c|c|c|c|c|c|c|c|c|c|c|c|}
\hline \multirow[t]{2}{*}{ Site } & & \multicolumn{4}{|c|}{ Class 0} & \multicolumn{4}{|c|}{ Class 1} & \multicolumn{4}{|c|}{ Class 2} \\
\hline & & Jan & Apr & Jul & Oct & Jan & Apr & Jul & Oct & Jan & Apr & Jul & Oct \\
\hline \multirow{3}{*}{ Sydney } & His & 4.0 & 3.3 & 2.3 & 2.8 & 7.6 & 6.7 & 5.8 & 5.3 & 12.6 & 14.2 & 14.0 & 11.8 \\
\hline & TPM & 4.5 & 3.8 & 2.8 & 3.3 & 7.7 & 7.0 & 6.4 & 5.8 & 13.0 & 14.3 & 14.4 & 12.2 \\
\hline & NP & 4.1 & 3.5 & 2.8 & 3.2 & 7.4 & 7.1 & 6.0 & 5.6 & 13.9 & 14.1 & 14.2 & 11.9 \\
\hline \multirow{3}{*}{ Melbourne } & His & 3.9 & 3.1 & 1.7 & 3.3 & 5.7 & 4.5 & 2.6 & 4.4 & 8.6 & 6.3 & 3.7 & 5.9 \\
\hline & TPM & 4.0 & 3.3 & 2.1 & 3.6 & 6.3 & 4.9 & 2.9 & 4.7 & 8.3 & 6.4 & 4.0 & 6.2 \\
\hline & NP & 4.0 & 3.2 & 2.0 & 3.5 & 5.9 & 4.7 & 2.8 & 4.5 & 9.1 & 6.5 & 3.6 & 5.7 \\
\hline
\end{tabular}

Table 4. Comparison of historical and generated mean, standard deviation and coefficient of skewness of dry spells.

\begin{tabular}{|c|c|c|c|c|c|c|c|c|c|c|c|c|c|}
\hline \multirow[t]{2}{*}{ Site } & & \multicolumn{4}{|c|}{ Mean (days) } & \multicolumn{4}{|c|}{ Standard deviation (days) } & \multicolumn{4}{|c|}{ Skewness } \\
\hline & & Jan & Apr & Jul & Oct & Jan & Apr & Jul & Oct & Jan & Apr & Jul & Oct \\
\hline \multirow{3}{*}{ Sydney } & His & 3.7 & 3.5 & 4.6 & 3.5 & 3.2 & 3.3 & 4.8 & 3.0 & 2.01 & 2.37 & 2.91 & 2.03 \\
\hline & TPM & 3.6 & 3.6 & 4.6 & 3.6 & 3.0 & 3.1 & 4.0 & 3.0 & 1.96 & 2.01 & 1.93 & 2.01 \\
\hline & NP & 3.7 & 3.7 & 4.7 & 3.6 & 3.3 & 3.5 & 4.8 & 3.3 & 2.16 & 2.35 & 2.44 & 2.40 \\
\hline \multirow{3}{*}{ Melbourne } & His & 5.5 & 3.5 & 2.3 & 2.9 & 5.0 & 3.1 & 1.7 & 2.4 & 1.93 & 2.99 & 1.83 & 2.53 \\
\hline & TPM & 5.4 & 3.5 & 2.4 & 2.9 & 4.9 & 2.9 & 1.8 & 2.4 & 1.94 & 1.90 & 2.07 & 2.17 \\
\hline & NP & 5.5 & 3.6 & 2.4 & 3.0 & 5.5 & 3.2 & 2.0 & 2.8 & 2.24 & 2.06 & 2.34 & 2.51 \\
\hline
\end{tabular}

Table 5. Comparison of historical and generated mean, standard deviation and coefficient of skewness of wet spells.

\begin{tabular}{|c|c|c|c|c|c|c|c|c|c|c|c|c|c|}
\hline \multirow[t]{2}{*}{ Site } & & \multicolumn{4}{|c|}{ Mean (days) } & \multicolumn{4}{|c|}{ Standard deviation (days) } & \multicolumn{4}{|c|}{ Skewness } \\
\hline & & Jan & Apr & Jul & Oct & Jan & Apr & Jul & Oct & Jan & Apr & Jul & Oct \\
\hline \multirow{3}{*}{ Sydney } & His & 2.3 & 2.8 & 2.7 & 2.2 & 1.9 & 2.7 & 2.7 & 1.6 & 2.38 & 3.28 & 3.59 & 1.95 \\
\hline & TPM & 2.3 & 2.7 & 2.6 & 2.1 & 1.8 & 2.3 & 2.2 & 1.6 & 2.21 & 2.17 & 2.20 & 2.18 \\
\hline & NP & 2.3 & 2.8 & 2.6 & 2.2 & 1.9 & 2.5 & 2.3 & 1.7 & 2.59 & 2.51 & 2.67 & 2.37 \\
\hline \multirow{3}{*}{ Melbourne } & His & 1.9 & 2.4 & 2.6 & 2.4 & 1.2 & 1.9 & 2.1 & 1.8 & 1.71 & 2.33 & 2.08 & 2.01 \\
\hline & TPM & 1.9 & 2.4 & 2.6 & 2.4 & 1.3 & 1.8 & 2.0 & 1.8 & 2.11 & 2.13 & 2.07 & 2.04 \\
\hline & NP & 1.9 & 2.4 & 2.5 & 2.4 & 1.3 & 2.0 & 2.2 & 1.9 & 2.35 & 2.37 & 2.58 & 2.23 \\
\hline
\end{tabular}

also be seen from Table 6 that the nonparametric model preserved the correlation between daily rainfall on class 2 wet days while the TPM method did not preserve for all the months. This is the only difference in performance between the two approaches with regard to daily statistics. 
Table 6. Comparison of historical and generated maximum dry and wet spell lengths and correlation between daily rainfall for class 2 wet days.

\begin{tabular}{|c|c|c|c|c|c|c|c|c|c|c|c|c|c|}
\hline \multirow[t]{2}{*}{ Site } & \multirow[t]{2}{*}{ Model } & \multicolumn{4}{|c|}{ Max dry spell length (days) } & \multicolumn{4}{|c|}{ Max wet spell length (days) } & \multicolumn{4}{|c|}{ Correlation (class 2 wet days) } \\
\hline & & Jan & Apr & Jul & Oct & Jan & Apr & Jul & Oct & Jan & Apr & Jul & Oct \\
\hline \multirow{3}{*}{ Sydney } & His & 22 & 24 & 47 & 21 & 15 & 29 & 26 & 11 & 0.136 & 0.230 & 0.220 & 0.139 \\
\hline & TPM & 22 & 22 & 28 & 22 & 14 & 17 & 16 & 12 & 0.056 & 0.130 & 0.130 & 0.076 \\
\hline & NP & 24 & 26 & 35 & 27 & 16 & 20 & 19 & 14 & 0.132 & 0.241 & 0.177 & 0.134 \\
\hline \multirow{3}{*}{ Melbourne } & His & 31 & 35 & 12 & 23 & 9 & 18 & 15 & 16 & 0.212 & 0.311 & 0.293 & 0.197 \\
\hline & TPM & 33 & 21 & 14 & 19 & 10 & 14 & 15 & 14 & 0.202 & 0.251 & 0.241 & 0.231 \\
\hline & NP & 40 & 23 & 16 & 22 & 10 & 16 & 19 & 15 & 0.209 & 0.259 & 0.306 & 0.198 \\
\hline
\end{tabular}

Table 7. Comparison of historical and generated monthly statistics.

\begin{tabular}{|c|c|c|c|c|c|c|c|c|c|c|c|c|c|}
\hline & & \multicolumn{6}{|c|}{ Sydney } & \multicolumn{6}{|c|}{ Melbourne } \\
\hline Parameter & Model & Jan & Mar & May & Jul & Sep & Nov & Jan & Mar & May & Jul & Sep & Nov \\
\hline \multirow{3}{*}{$\begin{array}{l}\text { Mean } \\
(\mathrm{mm})\end{array}$} & Hist & 104 & 133 & 126 & 98 & 71 & 83 & 48 & 53 & 58 & 48 & 59 & 60 \\
\hline & TPM & 104 & 137 & 124 & 102 & 71 & 85 & 49 & 54 & 61 & 51 & 61 & 61 \\
\hline & NP & 105 & 132 & 122 & 97 & 72 & 84 & 49 & 52 & 58 & 47 & 59 & 62 \\
\hline \multirow{3}{*}{$\begin{array}{c}\text { Std Dev } \\
(\mathrm{mm})\end{array}$} & Hist & 80 & 106 & 110 & 84 & 59 & 78 & 37 & 41 & 28 & 23 & 29 & 37 \\
\hline & TPM & 80 & 99 & 103 & 89 & 57 & 67 & 37 & 39 & 31 & 25 & 30 & 36 \\
\hline & NP & 88 & 102 & 98 & 91 & 62 & 72 & 39 & 40 & 32 & 26 & 30 & 39 \\
\hline \multirow{3}{*}{ Skew } & Hist & 1.33 & 1.46 & 1.71 & 1.02 & 1.60 & 3.00 & 1.23 & 1.15 & 0.53 & 2.01 & 1.48 & 1.13 \\
\hline & TPM & 1.59 & 1.40 & 1.38 & 1.61 & 1.65 & 1.84 & 1.27 & 1.35 & 1.12 & 1.47 & 1.27 & 1.14 \\
\hline & NP & 1.74 & 1.45 & 1.35 & 1.78 & 1.92 & 2.10 & 1.39 & 1.42 & 1.07 & 1.28 & 1.12 & 1.35 \\
\hline \multirow{3}{*}{ Correl. } & Hist & 0.12 & 0.13 & 0.10 & 0.04 & 0.09 & 0.08 & -0.06 & 0.11 & -0.02 & 0.05 & 0.08 & 0.20 \\
\hline & TPM & 0.01 & 0.04 & 0.03 & 0.04 & 0.02 & 0.03 & 0.00 & 0.01 & 0.02 & 0.03 & 0.03 & 0.02 \\
\hline & NP & 0.05 & 0.07 & 0.02 & 0.12 & 0.02 & 0.06 & -0.01 & 0.03 & 0.05 & 0.10 & 0.02 & 0.06 \\
\hline \multirow{3}{*}{ Min } & Hist & 0.05 & 0.06 & 0.03 & 0.02 & 0.03 & 0.02 & 0.01 & 0.07 & 0.07 & 0.20 & 0.23 & 0.11 \\
\hline & TPM & 0.06 & 0.07 & 0.03 & 0.02 & 0.05 & 0.06 & 0.02 & 0.04 & 0.17 & 0.22 & 0.21 & 0.11 \\
\hline & $\mathrm{NP}$ & 0.03 & 0.04 & 0.03 & 0.01 & 0.03 & 0.04 & 0.02 & 0.04 & 0.13 & 0.15 & 0.15 & 0.08 \\
\hline \multirow{3}{*}{ Max } & Hist & 3.74 & 3.91 & 4.66 & 3.42 & 5.01 & 6.23 & 3.67 & 3.62 & 2.46 & 3.70 & 3.43 & 3.46 \\
\hline & TPM & 4.22 & 3.90 & 4.34 & 4.67 & 4.44 & 4.51 & 3.95 & 3.87 & 2.91 & 3.11 & 2.90 & 3.18 \\
\hline & NP & 4.61 & 4.07 & 4.21 & 5.29 & 5.06 & 5.14 & 4.13 & 4.07 & 3.12 & 3.29 & 3.02 & 3.51 \\
\hline \multirow{3}{*}{$\begin{array}{c}\text { No } \\
\text { rainfall } \\
(\%)\end{array}$} & Hist & 0.0 & 0.0 & 0.0 & 0.0 & 0.0 & 0.0 & 0.0 & 0.0 & 0.0 & 0.0 & 0.0 & 0.0 \\
\hline & TPM & 0.0 & 0.0 & 0.0 & 0.1 & 0.0 & 0.0 & 0.2 & 0.1 & 0.0 & 0.0 & 0.0 & 0.0 \\
\hline & NP & 0.0 & 0.0 & 0.1 & 0.2 & 0.2 & 0.1 & 0.3 & 0.0 & 0.0 & 0.0 & 0.0 & 0.0 \\
\hline
\end{tabular}

Table 8. Comparison of historical and generated annual parameters.

\begin{tabular}{|c|c|c|c|c|c|c|c|c|c|c|c|c|}
\hline \multirow[t]{2}{*}{ Site } & \multirow[t]{2}{*}{ Model } & \multirow{2}{*}{$\begin{array}{l}\text { Mean } \\
(\mathrm{mm})\end{array}$} & \multirow{2}{*}{$\frac{\mathrm{SD}}{(\mathrm{mm})}$} & \multirow[t]{2}{*}{ Skew } & \multirow[t]{2}{*}{ Correl } & \multirow[t]{2}{*}{ Min } & \multirow[t]{2}{*}{ Max } & \multirow[t]{2}{*}{ Range } & \multicolumn{4}{|c|}{ Low rainfall sums } \\
\hline & & & & & & & & & $2 \mathrm{yr}$ & $3 y r$ & $5 y r$ & $10 \mathrm{yr}$ \\
\hline \multirow{3}{*}{ Sydney } & His & 1220 & 325 & 0.62 & 0.13 & 0.48 & 1.80 & 5.57 & 1.27 & 2.04 & 3.67 & 7.98 \\
\hline & TPM & 1244 & 329 & 0.69 & 0.01 & 0.45 & 1.86 & 5.01 & 1.20 & 2.01 & 3.77 & 8.39 \\
\hline & NP & 1214 & 321 & 0.54 & 0.03 & 0.47 & 1.84 & 5.43 & 1.21 & 2.00 & 3.66 & 8.06 \\
\hline \multirow{3}{*}{ Melbourne } & His & 660 & 128 & 0.02 & 0.01 & 0.50 & 1.47 & 2.27 & 1.31 & 2.17 & 4.10 & 8.89 \\
\hline & TPM & 683 & 127 & 0.86 & 0.04 & 0.61 & 1.58 & 5.27 & 1.44 & 2.35 & 4.19 & 9.07 \\
\hline & NP & 656 & 139 & 0.32 & 0.19 & 0.55 & 1.61 & 5.90 & 1.28 & 2.06 & 3.70 & 8.07 \\
\hline
\end{tabular}

\subsection{Monthly Statistics}

Comparison of the historical and generated monthly parameters is given in Table 7 . Both models preserved all the parameters except the correlation between monthly rainfalls. The NP approach seems to be able to produce correlations that are slightly closer to the historical values than the TPM approach.

\subsection{Annual Statistics}

Comparison of the historical and generated parameters of annual rainfall is given in Table 8 . All the parameters of annual rainfall have been preserved satisfactorily, with two exceptions. The TPM method overestimates the mean annual rainfalls by $2-3 \%$. This is consistent with the results of Zhou et al. (2002), who tested the TPM model at 21 locations. Zhou et al. (2002) also showed that the TPM approach does not 
reproduce annual lag-one autocorrelations that are significantly different from zero. The lag one autocorrelation coefficients are not reproduced here by either TPM or NP. Again, the NP approach seems to be able to produce closer correlations than the TPM approach. The historical and generated standard deviation of 2-, 3-, 5- and 10-year sums are given in Table 9. Both models appear to preserve these statistics satisfactorily.

Table 9. Comparison of the standard deviation of 2-, 3-, 5- and 10-year rainfall sums.

\begin{tabular}{|l|l|l|l|l|c|}
\hline Site & Model & $2 \mathrm{yr}$ & $3 \mathrm{yr}$ & $5 \mathrm{yr}$ & $10 \mathrm{yr}$ \\
\hline \multirow{4}{*}{ Melbourne } & His & 180 & 191 & 319 & 497 \\
\cline { 2 - 6 } & TPM & 181 & 222 & 289 & 418 \\
\cline { 2 - 6 } & NP & 209 & 273 & 394 & 629 \\
\hline \multirow{3}{*}{ Sydney } & His & 450 & 569 & 852 & 1368 \\
\cline { 2 - 6 } & TPM & 460 & 567 & 740 & 1058 \\
\cline { 2 - 6 } & NP & 451 & 563 & 759 & 1119 \\
\hline
\end{tabular}

The mean, standard deviation and the lag one autocorrelation coefficient of the annual number of wet days are given in Table 10. Only the mean number of annual wet days has been preserved by both the models. The TPM model failed to preserve the standard deviation and the lag one autocorrelation coefficient of the annual number of wet days while the NP model preserved both. This is to be expected as the NP model took account of the wetness state of the medium to long term period in determining the occurrence of rainfall, whereas the TPM model was entirely dependent on the state of the previous day.

Table 10. Comparison of mean, standard deviation and lag one autocorrelation of the annual number of wet days.

\begin{tabular}{|l|l|l|r|c|}
\hline Site & & Mean & Std dev & Correl \\
\hline \multirow{3}{*}{ Sydney } & His & 146.7 & 20.9 & 0.30 \\
\cline { 2 - 5 } & TPM & 143.6 & 13.5 & -0.01 \\
\cline { 2 - 5 } & NP & 143.1 & 22.6 & 0.33 \\
\hline \multirow{3}{*}{ Melbourne } & His & 152.8 & 17.2 & 0.31 \\
\cline { 2 - 5 } & TPM & 149.9 & 11.9 & 0.00 \\
\cline { 2 - 5 } & NP & 148.8 & 18.2 & 0.36 \\
\hline
\end{tabular}

\section{CONCLUSIONS}

The transition probability matrix (TPM) model and the nonparametric approach to generate daily rainfall data were compared using data from Melbourne and Sydney. Both approaches preserved most of the daily, monthly and annual characteristics, but failed to preserve the correlations in monthly and annual rainfall. However, the nonparametric approach preserved the correlation between daily rainfall on Class 2 wet days, and the variability and persistence in the annual number of wet days, while the TPM model failed to preserve them.

\section{REFERENCES}

Boughton, W. C., A daily rainfall generating model for water yield and flood studies. Report 99/9, CRC for Catchment Hydrology, Monash University, Melbourne, 21pp,1999.

Harrold, T.I. Stochastic generation of daily rainfall for catchment water management studies. PhD Thesis, School of Civil Engineering, University of New South Wales, Sydney, 2002.

Harrold, T. I., A. Sharma and S. J. Sheather, Representation of long-term variability in daily rainfall generation. Hydrology and Water Resources Symposium, Institution of Engineers, Australia, 2002.

Lall, U., B. Rajagopalan, D. G. Tarboton, A nonparametric wet/dry spell model for resampling daily precipitation. Water Resources Research, 32(9), 2803-2823, 1996.

Rajagopalan, B., U. Lall, and D. G. Tarboton, Nonhomogeneous Markov model for daily precipitation. Journal of Hydrologic Engineering, 1(1), 33-40,1996.

Sharma, A., D. G.Tarboton, and U. Lall, Streamflow simulation: A nonparametric approach. Water Resources Research, 33(2), 291-308, 1997.

Sharma, A. and U. Lall, A nonparametric approach to daily rainfall simulation. Mathematics and Computers in Simulation, 48, 367-371, 1999.

Sharma, A. and R. O’Neill , A nonparametric approach for representing interannual dependence in monthly streamflow sequences. Water Resources Research, 138(7), 5-1:5-10, 2002.

Silverman, B. W. Density estimation for statistics and data analysis. Chapman and Hall, New York, 1986.

Srikanthan, R. and T.A. McMahon, Stochastic generation of rainfall and evaporation data. AWRC Technical Paper No. 84, 301pp, 1985.

Zhou, S. L., R. Srikanthan, T.A. McMahon, Q.J. Wang, and R. Nathan, Stochastic modeling of daily rainfall. Hydrology and Water Resources Symposium, Institution of Engineers, Australia, 2002. 